\title{
Study on CEI Network Model of Public Management
}

\author{
Dingsong Lan $^{1}$, Shouyan Cheng ${ }^{2}$ \\ ${ }^{1}$ Anshun University, Anshun, 561000, China \\ ${ }^{2}$ Guizhou Radio \& TV University, Guiyang, 550004, China
}

Keywords: ACEI model, Network, Public management, Intelligent scheduling, Oracle server, Relevance

\begin{abstract}
This paper introduces the network CEI model in the city public management and the use of data mining association rules proposes intelligent sorting optimization algorithm for public affairs management, they improve the intelligent level and the office automation level of the public management. In order to verify the effectiveness and the reliability of the algorithm, this paper designs the CEI decision system of network city management. The system uses the Oracle server to manage data, and the data algorithm is encrypted, so the public management has the ability to make priority emergency things using relevance analysis, and the various management things are sorted according to relevance level and customer requirements weights, finally they are summarized to the decision system, which improves the level of automation of office.
\end{abstract}

\section{Introduction}

CEI public management mode makes various social economic subject of city as customers, according to customer demand as the guidance, it uses innovative management and operation means, with the aid of advanced information-based network system as the nerve tissue, connects the public management departments of all kinds of things as a whole, which is the adaptive ability of public management [1, 2]. This paper introduces the data association algorithm in the CEI model, the design of the intelligent optimization algorithm of transaction processing, public management has the ability to prioritize emergency things, and can be a variety of things according to the relevance of the management rank and customer requirements weights are sorted, improve the level of automation of office.

\section{The CEI Mode Frame Design for Network City Management}

The model of network city management pattern mainly is to use internet function to establish a link between customer needs and decision-making system, and sorts the affairs through intelligent optimization algorithms, which improves the office automation level of public management [3]. The CEI working mode is consist of the customer interface, information network layer, function layer, organization structure layer. The overall framework of the CEI public management mode is shown in Figure 1.

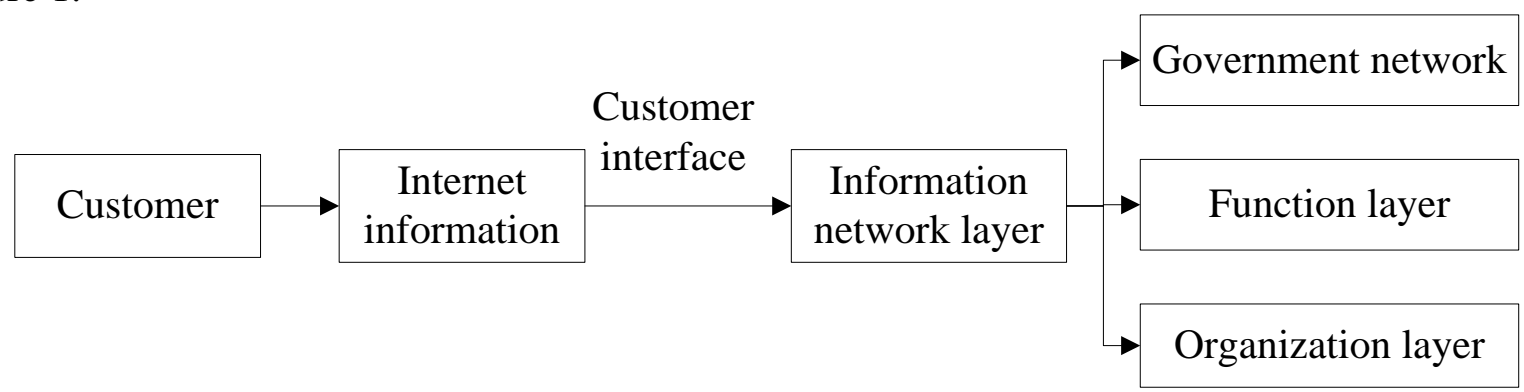

Fig. 1 Network CEI model framework

As shown in Figure 1, the core of city network management is information network layer and function layer [4]. The information network layer is responsible for the registration, storage, 
processing, transmission; while the functional layer completes the unified implementation, management and decision making support on the basis of information network layer.

\section{The Correlation Analysis of Network CEI Model}

Network management can use the relevance of affairs to improve the office automation level. In the general public management transaction process, there is a correlation between multiple transactions, assuming correlation function is $y=f\left(x_{i}\right)[5,6]$. According to the association analysis of Hermite interpolation, $S_{3}(x)$ in each interval $\left[x_{i}, x_{i+1}\right]$ can be represented as shown in formula (1).

$$
S\left(x_{i+\frac{1}{2}}\right)=\frac{1}{2}\left[f\left(x_{i}\right)+f\left(x_{i+1}\right)\right] .
$$

In order to summary the correlation of general affairs, this paper sorts the affairs emergency and customer needs weights, and establishes boundary value equation of comprehensive transaction, as shown in the formula (2):

$$
\left\{\begin{array}{l}
S_{3}\left(x_{i}-0\right)=S_{3}\left(x_{i}+0\right) \\
S_{3}^{\prime}\left(x_{i}-0\right)=S_{3}^{\prime}\left(x_{i}+0\right) \\
S_{3}^{\prime \prime}\left(x_{i}-0\right)=S_{3}^{\prime \prime}\left(x_{i}+0\right), \quad i=1,2, \ldots n-1
\end{array} .\right.
$$

According to the three order spline interpolation model, combined with computer relevance boundary conditions as shown in Figure 2, it can get the boundary value of algorithm.

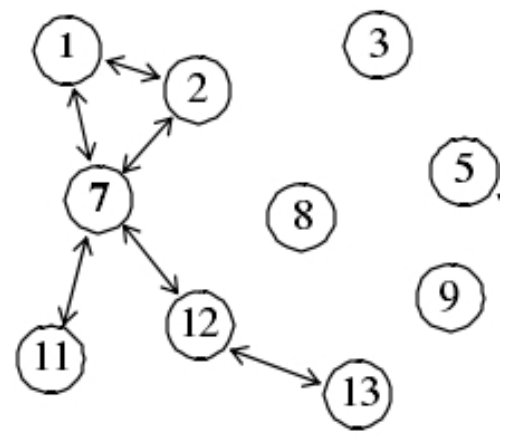

Fig. 2 The correlation analysis for boundary value

Figure 2 shows the computer optimal relevance searching boundary condition for city network management CEI model. From Figure 2 it can be seen, the endpoints of three associated spline function satisfies formula (3).

$$
\begin{aligned}
& S_{3}\left(x_{0}+0\right)=S_{3}\left(x_{n}-0\right), S_{3}^{\prime}\left(x_{0}+0\right)=S_{3}^{\prime}\left(x_{n}-0\right) . \\
& S_{3}^{\prime \prime}\left(x_{0}+0\right)=S_{3}^{\prime \prime}\left(x_{n}-0\right)
\end{aligned} .
$$

At two ends of each interval $\left[x_{i}, x_{i+1}\right]$, there is:

$$
S_{3}^{\prime \prime}\left(x_{i}\right)=\frac{6\left(y_{i+1}-y_{i}\right)}{h_{i}^{2}}-\frac{4 m_{i}+2 m_{i+1}}{h_{i}} \text {. }
$$

It can be simplified to:

$$
\left(1-\lambda_{i}\right) m_{i-1}+2 m_{i}+\lambda_{i} m_{i+1}=\beta_{i} \text {. }
$$

According to the least square method, the correlation equation can be obtained through linear fitting as shown in formula (6).

$$
Q(a, b)=\sum_{i=1}^{N}\left[y_{i}-\left(a+b x_{i}\right)\right]^{2} .
$$

By solving the least square algorithm equation, the correlation equations can be obtained as shown in formula (7).

$$
\left\{\begin{array}{l}
a N+b \sum x_{i}=\sum y_{i} \\
a \sum x_{i}+b \sum x_{i}^{2}=\sum x_{i} y_{i}
\end{array} .\right.
$$


In order to protect the safety of Oracle server, it should ensure that all content ownership of ORACLE HOME/bin directory can be used by Oracle users [7]. In order to strengthen the security of database in the network, the user should use password to access to the database through encryption method. The main used code is as follows:

GRANT ALTER ANY TABLE TO "DLSYS";

GRANT CREATE ANY INDEX TO "DLSY5";

GRANT CREATE ANY PROCEDURE TO "DLSYS";

......

Increasing the SDE9.X permissions

GRANT ALTER ANY INDEX to "SDE";

GRANT ALTER ANY TABLE to "SDE";

GRANT ANALYZE ANY to "SDE";

Support the safety control authority operation

GRANT ALTER ON "DLSYS"."TCSYSINIT" TO "DLINIT";

GRANT INSERT ON "DLSYS"."TCSYSINIT" TO "DLINIT";

GRANT SELECT ON "DLSYS"."TCSYSINIT" TO "DLINIT";

GRANT UPDATE ON "DLSYS"."TCSYSINIT" TO "DLINIT";

GRANT SELECT ANY TABLE TO "DLINIT";

\section{The Construction of Digital CEI City Public Management Network}

In order to verify the validity and reliability of city management network CEI model optimization algorithm designed in second section, this paper establishes the CEI city public management system, and uses this system to do relevance search and intelligent sorting on city public affairs [8,9]. The use of hardware and software configuration is as shown in Table 1.

Table 1. The main use of hardware equipment and software

\begin{tabular}{|c|c|c|c|}
\hline \multirow{4}{*}{ System } & Classification & System & Number \\
\hline \multirow{4}{*}{$\begin{array}{c}\text { City network information } \\
\text { CEI management system }\end{array}$} & Server & & 6 \\
\cline { 2 - 4 } & Operation system & Windows XP Server & 2 \\
\cline { 2 - 4 } & GIS software & ESRI Arcgis 10 Server & 2 \\
\cline { 2 - 4 } & Middleware & Oracle Weblogic 10.2.2 & 1 \\
\cline { 2 - 4 } & Safety equipment & Intrusion detection & 2 \\
\cline { 2 - 4 } & Storage & Disk array & 1 \\
\hline
\end{tabular}

Table 1 shows the hardware equipment and the software system, it includes the operating system, GIS software, security detection and storage equipment. The intermediate data uses Oracle database software system.

As shown in Figure 3 it shows the association model of city management, this method has good robustness. The association degree increases gradually from bottom to top, finally the top things belong to the highest priority [10]. Use this thought the city network management system is designed as shown in Figure 4. 


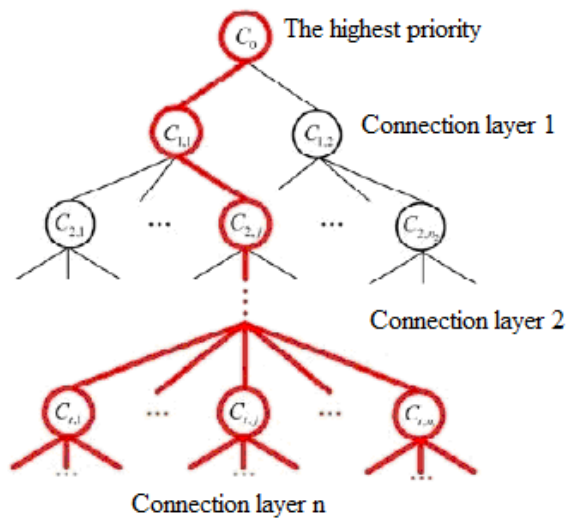

Fig. 3 Data association model diagram

Figure 4 shows the schematic diagram of the network city public management system. This figure uses the mobile phone and computer to connect transaction management, and carries on the correlation analysis [11]. The results are summarized to the emergency command center, and are made decision according to the priority level of affairs.

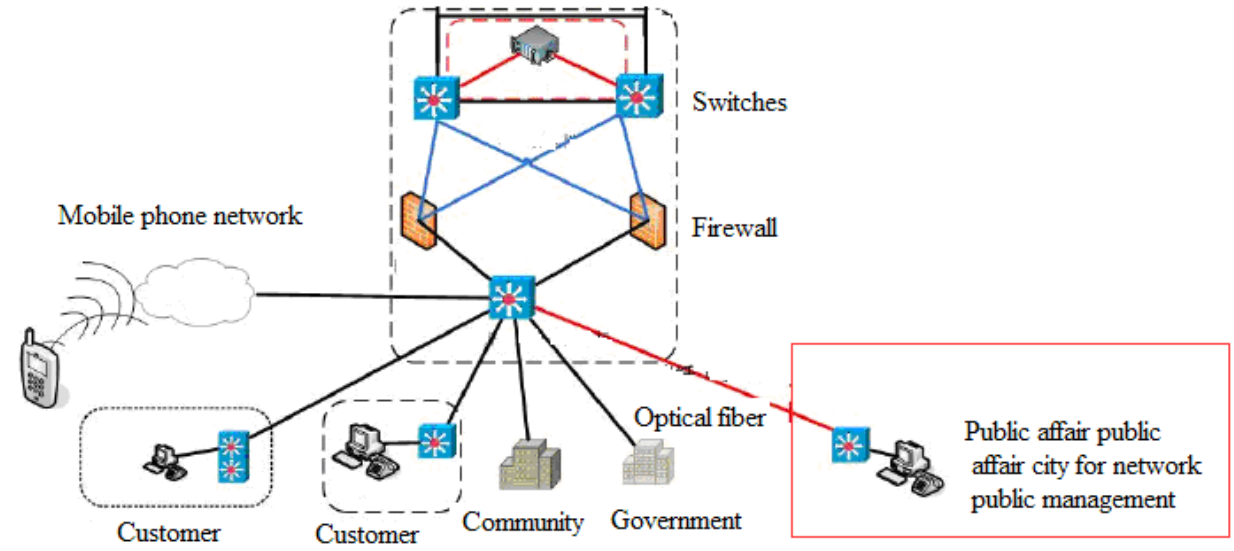

Fig. 4 Network city management CEI model

Figure 5 shows the calculation results of relational path for the network relational path management center [12]. From the chart objects associated index can be seen, the association index can be done optimize path searching, finally the priority processing red cloud can be obtained using priority processing path.

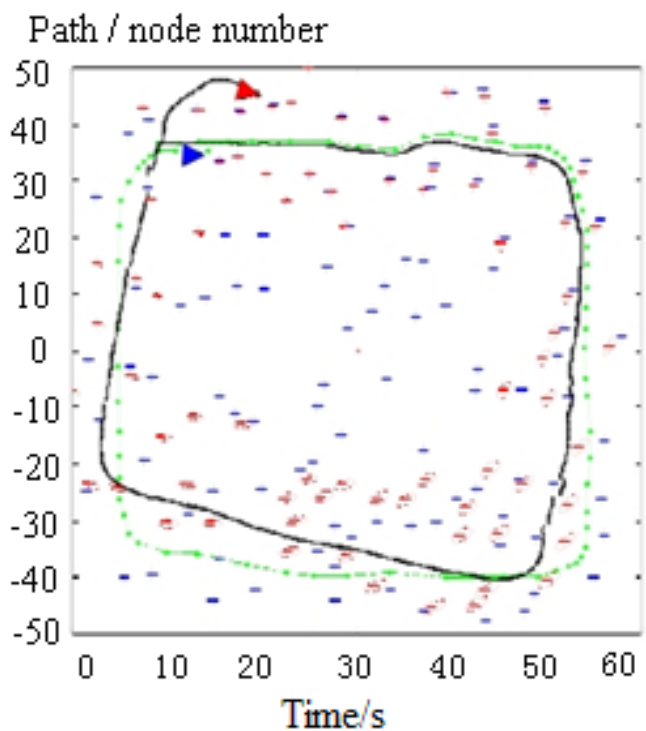

Fig. 5 CEI association analysis for network city management 


\section{Summary}

This paper established CEI mathematical model of network city management, and introduces the correlation analysis algorithm, and the public affairs management has intelligent priority sorting function. This paper uses the Oracle server to manage data, and designs CEI system of city network intelligent management using the relevance search. This system has analysis function of things relevance and emergency weight. Through the testing, this paper gets emergency things priority red cloud, so as to verify the effectiveness of the system, which provides technical reference for the design of city public management network system.

\section{References}

[1] Y.T. Wen, L.N. Peng. Application of computer technology in city planning. Value engineering, 2012, 2(31): 23-27.

[2] J. Wen. From a single passive to multiple linkage - construction and perfect of China city grid social management mode. Learning and exploration, 2012, 4(2): 101-104.

[3] X. He, X.B. Wu. City grid management and fine service. Hubei adult college education, 2012, 4(1): 112-114.

[4] L. Zhou. Analysis on the construction of Pudong new area Shanghai city grid management. Management and technology for small and medium enterprise, 2012, 3(8): 45-49.

[5] F. Zhao. Study on the city construction and management new ideas based on the GIS technology. Technology innovation herald, 2012, 3(22): 78-81.

[6] J. Liu. Establishment and optimization of modern city management law system. Shanghai city management, 2011, 5(3): 36-39.

[7] L.Q. Guo. Decision idea of modern city fine management. China construction information, 2012, 4(2): 24-26.

[8] Z.R. Chi, H.C. Wang, Y. Chen. Explore of Shanghai city grid management model. Science and technology countermeasures, 2013, 2(1): 98-100.

[9] R. Jiang. The status and trends of digital city project management. Chinese information circles, 2012, 2(4): 34-36.

[10]H.T. Sun Hong, B. Yuan. Risks and control strategies for our country commercial bank supply chain financial. The market aspect, 2012, 4 (7): 23-24.

[11] J.Z. Xu. The position of the small and medium-sized enterprise in the national economy. Private science and technology, 2012, 2(12): 75-78.

[12]X. Zhang. Small and medium-sized enterprises play a decisive role in structural adjustment. Shanghai securities news, 2012(2): 43-46. 